\title{
Dynamic tax competition between symmetric countries with multiple strategic investors
}

Kaushal Kishore ( $\nabla$ kishoreminx@gmail.com )

Indian Institute of Science Education and Research Bhopal

\section{Research Article}

Keywords: Preferential Taxation, Non-preferential Taxation, Dynamic Tax Competition, Tax Holidays, Home Bias

Posted Date: November 5th, 2021

DOI: https://doi.org/10.21203/rs.3.rs-1052578/v1

License: (c) (i) This work is licensed under a Creative Commons Attribution 4.0 International License. Read Full License 


\title{
Dynamic tax competition between symmetric countries with multiple strategic investors
}

\author{
kaushal Kishore* \\ Assistant Professor \\ Department of Economic Sciences \\ Indian Institute of Science Education and Research Bhopal \\ Bhopal Bypass Road, Bhauri \\ Madhya Pradesh, India
}

November 5, 2021

\begin{abstract}
Two symmetric countries compete over two-period under a non-preferential taxation regime to attract multiple investors where investors are strategic and investments are sunk once invested. Contrary to the existing results, we find that tax holidays do not arise during the initial period. Equilibria in mixed strategies arise in both periods where competing countries set strictly positive tax rates during the initial period. Strategic interaction between large investors reduces competition and increases tax rates during the initial period. We provide full characterization and uniqueness of equilibria in mixed strategies.
\end{abstract}

JEL classification: F21, H21, H25, H87

Keywords: Preferential Taxation, Non-preferential Taxation, Dynamic Tax Competition, Tax Holidays.

\section{Introduction}

Returns on investments can be fully expropriated when investments are sunk once invested. This deters foreign investments. The hold-up problem due to the threat of expropriation has been well studied ${ }^{1}$. In particular, Kehoe (1989)

\footnotetext{
*" Competing interests: The authors declare no competing interests". I am thankful to seminar participants at IISER Bhopal for their valuable comments and suggestions. All remaining errors are mine. Email: kaushal@iiserb.ac.in Ph: +91 7496088192

${ }^{1}$ See for example; Eaton and Gersowitz(1983), Thomas and Worrall (1994), Konrad and Lommerud (2001)
} 
shows that competition between governments can solve the hold-up problem. Konrad and Lommerud (2001) show that incomplete information may partially solve this problem. In the literature on tax competition, Bond and Samuelson (1986) show that when investors do not know the productivity of competing countries, a country with higher productivity offers tax holidays during the initial period to signal its higher productivity. Moreover, governments also face dynamic inconsistency problems when they cannot commit to future tax rates ${ }^{2}$. Janeba (2000) shows that firms may build capacity in more than one country when a country cannot commit to future tax rates. Kishore and Roy (2014) show that a non-preferential taxation regime can solve hold-up as well as dynamic inconsistency problems when a single country wishes to attract investors that differ in their cost of mobility ${ }^{3}$.

The paper is also related to a huge literature on "tax competition" ${ }^{4}$. Authors argue that the cost of capital relocation is falling over time. Large multinationals choose their location based on tax preferences offered by host governments. This leads to "race to the bottom" effect where tax rates on many forms of capital are close to zero. Authors argue that countries are increasingly adopting preferential taxation regimes where they set a lower tax rate on foreign capital compared to domestic capital. This leads to competition among nations to attract footloose foreign investments. Various measures have been taken through supranational agencies such as OECD to promote cooperation on international taxation and encourage countries to adopt non-preferential taxation regimes ${ }^{5}$. Various authors compare tax revenues of competing countries under two different taxation regimes in a static setting: (i) competing countries jointly adopt non-preferential taxation regime that restricts them to setting an equal tax rate on capital with different mobility, vintages, nationality, etc., and (ii) competing countries adopt preferential taxation regime where they are free to set different tax rates for different capital bases ${ }^{6}$. Authors find that non-preferential taxation regimes are desirable under certain circumstances. Haupt and Peters (2005) and Kishore (2019) find that when investors have home bias, non-preferential regimes generate greater tax revenues compared to preferential regimes. Bucovetsky and Haufler (2007) show that when countries differ in their size of domestic capital bases, non-preferential regimes generate greater tax revenues. In particular, Janeba and Peters (1999) show that a country has unilateral incentives to commit to non-preferential regimes even when the competitor adopts preferential taxation. The literature on dynamic tax competition is relatively scarce. Kishore (2020) also shows that a country has an incentive to commit to a non-preferential regime unilaterally when countries compete to attract one

\footnotetext{
${ }^{2}$ See for example; Janeba (2000), Kishore and Roy (2014), Kishore (2017, 2021)

${ }^{3}$ However, Kishore $(2017,2017)$ show the opposite is true when investors are large or the cost of capital relocation decreases over time

${ }^{4}$ See Wilson (1999) for a survey on tax competition

${ }^{5}$ See OECD (2004): The OECD's project on harmful tax practices.

${ }^{6}$ See for example; Haupt and Krieger (2020), Haupt and Peters (2005), Janeba and Peters (1999), Janeba and Smart (2003), Keen (2001), Kishore (2019), Mongrain and Wilson (2018), Wilson (2005), Bucovetsky and Haufler (2007), Merceau, Mongrain, and Wilson (2010), Wang (2004)
} 
large investor in each period and investments are partially sunk. Moreover, competition to attract the investor during the initial period results in countries offering "tax holidays" during the initial period. Kishore (2021) shows that the same is true when the size of capital bases in different time periods are different. Moreover, countries set strictly positive tax rates during the initial period when the size of the foreign capital base in the later period is substantially larger than the size of the foreign capital base during the initial period. Therefore, the "hold-up" problem is substantially reduced when the size of the foreign capital base that enters the economy during the later period is large compared to the existing capital base.

The paper is also related to the literature on "switching cost", and competition between firms in the presence of loyal consumer bases. The nature of equilibria we analyze has been studied in Bertrand type competition between firms with loyal customers (See Narasimhan (1988)), or when customers have switching costs (Farrell and Klemperer (2007)). The mixed strategy Nash equilibrium in this paper is most closely related to Fisher and Wilson (1995). Fisher and Wilson (1995) look at the competition between firms for foreign consumers in the presence of tariffs.

We consider a two-period dynamic tax competition game where two investors (each owns one unit of capital) enter the economy during the initial period. Capital is fully sunk once investments are made. To keep the symmetry, we assume that one investor (owns two units of capital) enters during the later period. Similar to Konrad and Kovenock (2009), we assume that competing countries commit to non-preferential taxation regimes for the entire duration of the game. As far as we know, this is the first paper that looks at the competition for FDI where more than one investors enter the market during the initial period. In Konrad and Kovenock (2009) and Kishore (2020, 2021), a single investor enters the market in each period. Understanding the nature of competition in the presence of multiple investors during the initial period is important. In this case, tax competition during the later period is not necessarily asymmetric. We have a symmetric tax competition game as well in the later period when both countries attract investments during the initial period. The model captures strategic interaction between large multinationals which has not been captured in the literature before.

Equilibria in mixed strategies arise during the later period as well as in the initial period. We provide full characterization and provide proof of the uniqueness of all equilibria. The novel aspect of the result is that tax holidays do not arise during the initial period of the game even though the size of the capital bases in two periods are equal. Competing countries set strictly positive tax rates during the initial period. The paper shows that competition over multiple large investors provides an explanation for prevailing positive tax rates even when competition for foreign capital is very high. Moreover, the paper also shows that the hold-up problem is less acute when countries compete for multiple investors compared to the case when the competition takes place for a single investor. Strategic interaction between large strategic investors helps alleviate the hold-up problem. 


\section{Model}

We consider two identical countries/jurisdictions indexed by $i \in(A, B)$. The economy lasts for two periods, 1 and 2. Countries $(A, B)$ compete to attract investments from outside their jurisdictions. Competing countries have no domestic capital at the beginning of period 1 . At the beginning of period 1 , two investors (each owns one unit of capital) enter the market outside of the jurisdictions of competing countries. At the beginning of period 2, an investor with 2 units of capital enters the market outside of the jurisdictions of country $A$ and $B$. For simplicity, we assume that outside the two competing countries, the return on invested capital is equal to 0 . The return on investments in the country $A$ and $B$ is equal to 1 in each period.

We analyze this dynamic tax competition between two symmetric countries when at the beginning of the game countries commit to non-preferential taxation regime for the entire duration of the game. If a country commits to a nonpreferential taxation regime, it cannot set discriminating tax rates depending on the origin of the capital (domestic and foreign) or capital bases of different vintages (old investments and potential new investments). We assume that governments maximize tax revenues, and investors maximize net returns on investments after-tax payments. We further assume neither governments nor investors discount future income. The stages of the game can be described as below:

Stage 1: Both countries jointly adopt non-preferential taxation regimes for the entire duration of the game.

Stage 2: At the beginning of period 1, competing countries simultaneously announce the tax rates applicable in period 1 . The investors observe the prevailing tax rates and make an investment in country $A$ or country $B$. The maximum tax rate a country can set is equal to 1 . The tax rate can be negative, that is, a government can offer tax holidays during the initial period.

Stage 3: At the beginning of period 2, competing countries announce tax rates applicable for period 2 . The new investor observes prevailing tax rates and make an investment in country $A$ or country $B$. Governments receive taxes at the end of period 2 .

We look at the subgame-perfect Nash equilibrium of this three-stage dynamic game.

\section{Tax Competition in Period Two}

First, we look at the outcomes in period 2 when both countries attract one investor each in period 1.

\subsection{Symmetric Tax Competition in Period Two}

In this case, both countries obtain investments in period 1 . In period 2 , there is an investor with 2 units of capital that is perfectly mobile. Two countries 
are committed to non-preferential regimes, therefore, country $A$ and country $B$ set tax rates $t_{a}$ and $t_{b}$, respectively. The tax revenue of country $i \in(A, B)$, is represented as

$$
N P S T_{i}^{2}= \begin{cases}t_{i}+2 t_{i}, & \text { if } t_{i} \leq t_{j} \\ t_{i}, & \text { if } t_{i}>t_{j}\end{cases}
$$

We assume that when an investor is indifferent between making an investment in country $A$ and country $B$, it invests in country $A$. This does not affect the equilibrium.

Lemma 1 When both countries attract an investor each in period 1, a pure strategy Nash equilibrium does not exist in period 2.

The intuition for the above result is simple. When a country sets a relatively high tax rate, the competitor is willing to undercut to attract new investors. On the other hand, when the tax rate of a country is low, the competitor prefers maximizing tax revenues from the domestic capital base and forgo foreign investments. Given a pure strategy Nash equilibrium does not exist, we analyze a mixed strategy Nash equilibrium.

Consider a symmetric mixed strategy Nash equilibrium where competing countries randomize over the common support $\left[\frac{1}{3}, 1\right]$, with the distribution of taxes over the support denoted by $F$. The distribution function $F$ is convex and there is no probability mass over the support. Note that when a country sets $t_{i}=1$, it attracts new investments with zero probability and receives taxes only from the domestic capital base. Therefore, the equilibrium tax revenue is equal to 1 . When a country sets a tax rate of $\frac{1}{3}$ then it attracts the new investor with probability 1 . It is easy to argue that in no equilibrium a country sets a tax rate lower than $\frac{1}{3}$. Suppose country $i \in(A, B)$ sets $t_{i} \in\left(\frac{1}{3}, 1\right)$. With probability $1-F_{j}\left(t_{i}\right)$ it undercuts the tax rate of country $j$ and receives a tax revenue of $2 t_{i}\left(1-F_{j}\left(t_{i}\right)\right)$ from new investments. It also receives a tax revenue of $t_{i}$ from the domestic capital base. Because a country receives an equal revenue everywhere on the support, the following equality holds:

$$
t_{i}+2 t_{i}\left(1-F_{j}\left(t_{i}\right)\right)=1 \text {. }
$$

Rearranging the above equation we obtain

$$
F(t)=1+\frac{1}{2}\left(1-\frac{1}{t}\right), t \in\left[\frac{1}{3}, 1\right] .
$$

Lemma 2 describes the characterization of the mixed strategy Nash equilibrium.

Lemma 2 A unique symmetric mixed strategy Nash equilibrium exists in period 2 when both countries attract one investor each in period 1. The equilibrium tax revenue of competing countries is equal to 1 . Both countries randomize over the common support $\left[\frac{1}{3}, 1\right]$. There is no probability mass over the support. The distribution of taxes over the support is given by (2). 
Proof. The proof of Lemma 2 is similar to Lemma 4. See Appendix for the proof of Lemma 4.

A mixed strategy Nash equilibrium of this type has been analyzed before in the literature on tax competition. Wang (2004), Kishore (2019), Anderson and Konrad (2001), Wilson (2005), Marceau, Mongrain and Wilson (2007) consider tax competition in a static model with mobile and immobile capital bases, resulting in equilibria similar to the one described here. Similar equilibria also arise in the literature on switching cost (Farell and Klemperer (2007)). Narasimhan (1988) analyzed competition between consumers where a fraction of consumers are loyal to a particular firm, resulting in similar equilibria.

\subsection{Asymmetric Tax Competition in Period Two}

Now we look at the outcomes in period 2 when one country attracts both investors in period 1 . Without loss of generality we assume that country $A$ attracts both investors in period 1 .

Lemma 3 When one country attracts both investors in period 1, a pure strategy Nash equilibrium does not exist in period 2.

Proof. Same as Lemma 1. See Appendix for the proof of Lemma 1

The intuition for Lemma 3 is similar to Lemma 1 . As before, we analyze a mixed strategy Nash equilibrium of the game in period 2. Without loss of generality suppose country $A$ attracts both investors in period 1 . Consider a candidate for mixed strategy Nash equilibrium where country $A$ and country $B$ randomizes over the supports $\left[\frac{1}{2}, 1\right]$ and $\left[\frac{1}{2}, 1\right)$, respectively with distribution functions $F_{a}$ and $F_{b}$. When country $A$ sets $t_{\text {min }}$ and attracts the new investor with probability one, its tax revenues is equal to $4 t_{\min }$. When country $A$ sets a tax rate of 1 it receives a tax revenue of 2 with certainty. Therefore, the minimum tax revenue country $A$ receives in any equilibrium is 2 . Therefore, the minimum tax rate country $A$ sets in equilibrium is equal to $\frac{1}{2}$. In the proposed equilibrium, country $B$ sets a tax rate of 1 with probability zero. When country $A$ sets the tax rate equal to 1 , it attracts the new investor with probability zero and receives a tax revenue of 2 . Therefore, the equilibrium tax revenue of country $A$ is equal to 2 . When country $B$ sets the tax rate of $\frac{1}{2}$, it attracts the new investor with probability one, and receives a tax revenue of 1 . In Appendix we show that no country has a probability mass at the infimum of the support. Suppose country $A$ sets a tax rate $t_{a}$ such that $\frac{1}{2}<t_{a}<1$. It undercuts the tax rate of country $B$ with probability $\left(1-F_{b}\left(t_{a}\right)\right)$ and receives revenues of amount $2 t_{a}$ from the new investor. Country $A$ also receives tax revenues of $2 t_{a}$ with certainty from the domestic capital base. Therefore, the following equality holds:

$$
2 t_{a}+2 t_{a}\left(1-F_{b}\left(t_{a}\right)\right)=2 .
$$

Rearranging the above equality we obtain 


$$
F_{b}(t)=2\left(1-\frac{1}{2 t}\right), t \in\left[\frac{1}{2}, 1\right)
$$

Now suppose country $B$ sets a tax rate $t_{b}$ such that $\frac{1}{2}<t_{b}<1$. Country $B$ undercuts the tax rate of country $A$ with probability $\left(1-F_{a}\left(t_{b}\right)\right)$ and receives tax revenues of amount $2 t_{b}$ from the new investor. Therefore, the following equality holds:

$$
2 t_{a}\left(1-F_{a}\left(t_{b}\right)\right)=1
$$

Rearranging the above equality we obtain

$$
F_{a}(t)=1-\frac{1}{2 t}, t \in\left[\frac{1}{2}, 1\right]
$$

Note that $F_{a}(1)=\frac{1}{2}$. There is a probability mass, $m_{a}$, at the supremum of the support of country $A$, where

$$
m_{a}=\frac{1}{2}
$$

Lemma 4 describes the characterization of the mixed strategy Nash equilibrium and the equilibrium tax revenues of competing countries.

Lemma 4 When one country attracts both investors in period 1, a unique mixed strategy Nash equilibrium exists in period 2. The equilibrium tax revenues of country $A$ (that has 2 units of domestic capital base) and country $B$ are 2 and 1, respectively. Both countries randomize over the common support $\left[\frac{1}{2}, 1\right]$, with country $B$ setting the tax rate of 1 with zero probability. There is a probability mass, $m_{a} \equiv \frac{1}{2}$, at the supremum of the support of country $A$. The distributions of taxes over the supports of country $A$ and country $B$ are $F_{a}$ and $F_{b}$, respectively. $F_{a}$ and $F_{b}$ are given by (4) and (3), respectively.

Proof. See Appendix.

A mixed strategy equilibrium of this type arises when a firm with a loyal consumer base compete with a firm that has no loyal consumer base in Narasimhan (1988). In equilibrium, the tax revenue of the country with a domestic capital base (large country) is equal to that it can receive by completely expropriating the return of its domestic capital. On the other hand, the tax revenue of the country without a domestic capital base (small country) is considerably greater. Authors argue that one of the rationals for having non-preferential taxation regimes is asymmetry of capital bases of competing countries (See Bucovetsky and Haufler(2007)). Wilson (2005), and Marceau, Mongrain, and Wilson (2010) also find similar results. 


\section{Tax Competition in Period One}

We observed that tax revenues of competing countries depend on the number of investors it attracts in period 1. If a country attracts both investors its tax revenue is equal to 2 . On the other hand, when a country attracts one investor (or no investor) its tax revenue is equal to 1 . Therefore, a country is indifferent between attracting one investor and not receiving an investment in period 1 . Moreover, the difference in tax revenues in period 2 depending on whether a country attracts both investors or not is equal to 1 . Therefore, the minimum tax rebate a country is willing to offer in period 1 is equal to 1 .

First, we look at the decision of investors. Suppose both investors invest in one country. From Lemma 4, the distribution of taxes in period 2 is given by $F_{a} \equiv 1-\frac{1}{2 t}, t \in\left[\frac{1}{2}, 1\right]$, with a probability mass of $\frac{1}{2}$ at 1 . The density function is, $f_{a} \equiv \frac{1}{2 t^{2}}$. Therefore, when both investors invest in one country, the expected amount an investor pays in period $2, E_{a}^{2}$ is equal to,

$$
E_{a}^{2} \equiv \int_{\frac{1}{2}}^{1} t f(t) d t+\frac{1}{2} \equiv \frac{1}{2}(1+\log 2)
$$

Now suppose two investors invest in different countries. From Lemma 2, the distribution of taxes in period 2 is $F \equiv 1+\frac{1}{2}\left(1-\frac{1}{t}\right)$. There is no probability mass over the support is $f \equiv \frac{1}{2 t^{2}}$. Therefore, when two investors invest in different countries, the expected amount an investor pays in period $2, E^{2}$, is equal to:

$$
E^{2} \equiv \int_{\frac{1}{2}}^{1} t f(t) d t \equiv \frac{1}{2} \log 2 .
$$

From (6) and (7) we observe that an investor pays more in period 2 when both investors invest in the same country. Therefore, when two countries set an equal tax rate in period 1 , investors choose to invest in different countries. If a country undercuts the tax rate of the competitor by a margin of $\frac{1}{2}$, it attracts both investors in period 1 . The tax revenue of country $i$ in period $1, N P T_{i}$, is represented as:

$$
N P T_{i}= \begin{cases}2 t_{i}+2, & \text { if } t_{i}<t_{j}-\frac{1}{2} \\ t_{i}+1, & \text { if } t_{j}-\frac{1}{2} \leq t_{i} \leq t_{j}+\frac{1}{2} \\ 1, & \text { if } t_{i}>t_{j}+\frac{1}{2}\end{cases}
$$

Lemma 5 A pure strategy Nash equilibrium does not exist in period one. Proof. Proof is simple.

Suppose country $i$ sets $t_{i} \geq \frac{1}{2}$. The tax revenue of country $j$ when it undercuts by a margin of $\frac{1}{2}$ is equal to $2\left(t_{i}-\frac{1}{2}\right)+2 \equiv 2 t_{i}+1$. The tax revenue of country $j$ when it sets a tax rate marginally below $t_{i}+\frac{1}{2}$ is equal to $t_{i}+\frac{3}{2}$. Note that $2 t_{i}+1 \geq t_{i}+\frac{3}{2}$ when $t_{i} \geq \frac{1}{2}$. Therefore, when a country $i$ sets $t_{i}>\frac{1}{2}$, country $j$ undercuts by a margin of $\frac{1}{2}$ and attracts both investors. On the other hand, when country $i$ sets $t_{i}<\frac{1}{2}$, country $j$ sets a tax rate marginally below $t_{i}+\frac{1}{2}$ 
and attracts one investor in period 1. Given a pure strategy Nash equilibrium does not exist, we analyze Nash equilibria in mixed strategies.

Consider a symmetric mixed strategy Nash equilibrium where competing countries randomize over the common support $[0,1]$, and there is no probability mass over the support. If a country $i$ sets $t_{i}=\frac{1}{2}$, then it attracts one investor in period 1 with probability 1 . From (8), the tax revenue of country $i$ is equal to $\frac{3}{2}$. A country receives an equal tax revenue everywhere on its support. Therefore, the equilibrium tax revenue of competing countries is equal to $\frac{3}{2}$. Suppose country $i$ sets $t_{i} \in\left(\frac{1}{2}, 1\right)$. With probability $F_{j}\left(t_{i}-\frac{1}{2}\right)$ country $i$ does not attract an investor in period 1 and receives an amount 1 in tax revenues. With probability $\left(1-F_{j}\left(t_{i}-\frac{1}{2}\right)\right)$, country $i$ attracts one investor in period 1 and receives an amount $1+t_{i}$ in taxes. Therefore, we have

$$
F_{j}\left(t_{i}-\frac{1}{2}\right)+\left(1+t_{i}\right)\left(1-F_{j}\left(t_{i}-\frac{1}{2}\right)\right)=\frac{3}{2} .
$$

After rearranging the above equality we obtain

$$
F_{j}\left(t_{i}-\frac{1}{2}\right)=1-\frac{1}{2 t_{i}} .
$$

Similarly, suppose country $i$ sets $t_{i} \in\left(0, \frac{1}{2}\right)$. With probability $F_{j}\left(t_{i}+\frac{1}{2}\right)$, it attracts one investor in period 1 and receives an amount $\left(1+t_{i}\right)$ in taxes. With probability $\left(1-F_{j}\left(t_{i}+\frac{1}{2}\right)\right)$, it attracts both investors in period 1 and receives $2\left(1+t_{i}\right)$ in taxes. Therefore, we have the following equality:

$$
\left(1+t_{i}\right) F_{j}\left(t_{i}+\frac{1}{2}\right)+2\left(1+t_{i}\right)\left(1-F_{j}\left(t_{i}+\frac{1}{2}\right)\right)=\frac{3}{2} .
$$

After rearranging the above equality we obtain

$$
F_{j}\left(t_{i}+\frac{1}{2}\right)=2-\frac{3}{2\left(1+t_{i}\right)} .
$$

From (9) and (10), the distribution of taxes over the support is given as

$$
F(t)= \begin{cases}1-\frac{1}{1+2 t}, & \text { if } t \in\left[0, \frac{1}{2}\right] \\ 2-\frac{3}{1+2 t}, & \text { if } t \in\left[\frac{1}{2}, 1\right]\end{cases}
$$

It is easy to check that the distribution function is continuous at $\frac{1}{2}$, and there is no probability mass anywhere on the support. Lemma 6 describes the equilibrium. The uniqueness of the mixed strategy Nash equilibrium is provided in Appendix.

Proposition 1 When competing countries jointly adopt non-preferential taxation regimes during the initial stage of the game, a unique symmetric mixed strategy Nash equilibrium exists. The equilibrium tax revenue of competing countries is equal to $\frac{3}{2}$. Competing countries randomize with the distribution function $F(t)$ over the support $[0,1]$, where $F(t)$ is given by (11). 
Proof. See Appendix for the proof of uniqueness.

The equilibrium described above is most closely related to equilibria discussed in Fisher and Wilson (1995). Fisher and Wilson (1995) look at competition between two firms located in distinct geography and selling homogeneous products. In the presence of tariffs, a firm is willing to undercut the price of its competitor by a discrete margin (tariff amount) to sell in the foreign country when the price in the foreign country is high. On the other hand, when the price in the foreign country is low, a firm increases its price. This results in equilibria similar to the equilibrium described here. It is also related to Shilony (1977) and Varian (1980). Kishore (2020) also characterized a mixed strategy Nash equilibrium similar to ours in a tax competition game.

It is noteworthy that the equilibrium tax revenue of competing countries is greater than 1 . This differentiate the nature of competition when there are multiple large investors, compared to the case when there is a single investor. When both investors invest in the same country in period 1 , the expected tax payments in period 2 is larger. A country has to offer a larger tax rebates to both investors. Therefore, a country can set a tax rate higher than the competitor and still attract one investor in period 1 . This reduces competition in period 1 resulting in much higher tax rates in period 1 than previously observed in the literature. Kishore (2020) looks at competition for foreign investments when one investor enters the market in each period. The revenue of a country in period 2 that attracts the investor in period 1 is greater than the other country. This leads to stiff competition during the initial period to attract investments, resulting in tax holidays during the initial period. Konrad and Kovenock (2009)

look at an infinite horizon model where a single investor enters the economy in each period, and the country that attracts the investor during the initial period has agglomeration advantages in attracting investments during the later period. Again, competition to attract the investment during the initial period leads to competing countries offering tax holidays during the initial period. Bond and Samuelson (1986) consider competition between two countries for foreign investments when countries differ in their productivity (not observed by the investor). The country with a high productivity offers a tax holiday during the initial period to signal its higher productivity. In our case, a tax holidays is not observed during the initial period. Most foreign investments are made by large multinationals. Therefore, competition for multiple large investors provide another explanation for; how countries continue to set very high tax rates and attract foreign investments. Therefore, hold-up problem is less acute when competing countries compete for multiple investors compared to the case when they compete to attract a single investor.

\section{Conclusion}

When both countries attract one investor each in period 1 , the equilibrium tax revenues of competing countries in period 2 are equal to that a country gets 
by fully expropriating returns of its domestic capital base. Authors have found similar results in the literature on tax competition. When one country attracts both investors in period 1, then the tax revenue of the larger country (that attracts both investors) is equal to what it gets by fully expropriating returns of the domestic capital base. On the other hand, the tax revenue of the smaller country (that does not attract investments in period 1) is strictly greater than that it gets from fully expropriating returns of the domestic capital base (zero in this case). Authors have found similar results when countries with different sizes of immobile capital base compete for perfectly mobile capital.

An equilibrium in mixed strategies also arises in period 1. Both countries set tax rates greater than zero with probability one. A tax holiday does not arise. This is a novel result. In a dynamic setting, when competing countries compete for a single investor tax holidays arise during the initial period (e.g, Konrad and Kovenock (2009), Bond and Samuelson (1986) Kishore (2020, 2021)). Having multiple strategic investors changes the dynamics of competing during the initial period. An investor has to pay higher taxes during the later period when both investors invest in the same country. A relatively higher tax rebate has to be offered to both investors if a country wishes to attract both investors. This makes the tax rebate during the initial period relatively expensive. A country can set the tax rate higher than its competitor and yet attract investments. This reduces competition during the initial period. The outcome hints that competition over multiple large investors can be one reason why many countries set high tax rates even when investors are footloose. The outcome also suggests that the hold-up problem is less pronounced when competing countries compete

over multiple strategic investors. The effect of having multiple strategic investors has not been studied before in the literature on tax competition and offers an exciting venue for future research.

\section{References}

[1] Andersson, F., Konrad, K.A., 2003. Human capital investment and globalization in extortionary states. Journal of Public Economics, 87, 1539-1555.

[2] Bucovetsky, S., Haufler, A., 2007. Preferential Tax Regimes with Asymmetric Countries. National Tax Journal, 60, 789-795.

[3] Bond, E.W., Samuelson, L., 1986. Tax Holidays as Signals. The American Economic Review, 76, 820-826.

[4] Eaton, J., Gersovitz, M., 1983. Country risk: Economic aspects. In:Herring, R.J. (Ed.), Managing International Risk. Cambridge University Press, Cambridge, $75-108$.

[5] Fisher, E., Wilson, C., 1995. Price competition between two International Firms Facing Tariffs. International Journal of Industrial Organization 13, 6787. 
[6] Farrell, J., Klemperer, P., 2007. Coordination and lock-in: competition with switching costs and network effects, in: Armstrong, M., Porter, R. (Eds.), Handbook of Industrial Organization, Volume 3. Elsevier, Amsterdam, pp. 1967-207.

[7] Haupt, A., Krieger, T., 2020. The role of relocation in tax and subsidy competition. Journal of Urban Economics, 116.

[8] Haupt, A., Peters, W., 2005. Restricting preferential tax regimes to avoid harmful tax competition. Regional Science and Urban Economics, 35, 493507.

[9] Janeba, E., 2000. Tax competition when governments lack commitment: excess capacity as a countervailing threat. American Economic Review, 90, 1508-1519.

[10] Janeba, E., Peters, W., 1999. Tax evasion, tax competition and the gains from non-discrimination: The case of interest taxation in Europe. Economic Journal, 109, 93-101.

[11] Janeba, E., Smart, M., 2003. Is targeted tax competition less harmful than its remedies? International Tax and Public Finance, 10, 259-280.

[12] Keen, M., 2001. Preferential regimes can make tax competition less harmful. National Tax Journal, 54, 757-762.

[13] Konrad, Kai A., Kovenock, D., 2009. Competition for FDI with vintage investment and agglomeration advantages. Journal of International Economics, 79.2 (2009): 230-237.

[14] Kehoe, P. J., 1989. Policy cooperation among benevolent governments may be undesirable. Review of Economic Studies, 56, 289-296.

[15] Konrad, K.A., K.E. Lommerud, E.K., 2001. Foreign direct investment, intra-firm trade and ownership structure. European Economic Review, 45, 475-494.

[16] Kishore, K., 2020. Dynamic Tax Competition, Home Bias and the gain from Non-preferential Taxation Regimes: A case for unilateral commitment. working paper.

[17] Kishore, K., 2021. Falling cost of capital relocation and preferential taxation of foreign capital. working paper.

[18] Kishore, K., 2014. Dynamic Inconsistency and non-preferential taxation of foreign capital. Economics Letters, 124, 88-92.

[19] Kishore, K., 2017. Dynamic Inconsistency and preferential taxation of foreign capital. International Tax and Public Finance, 24, 381-396. 
[20] Kishore, K., 2019. Tax Competition, Imperfect Capital Mobility, and the gain from non-preferential agreements. The Journal of International Trade and Economic Development, 28, 755-774.

[21] Kishore, K., 2021. Competition for FDI with vintage investment and agglomeration advantages: A revisit. working paper.

[22] Kishore, K., 2021. Tax Competition between Symmetric Countries for Large Asymmetric Investors. working paper.

[23] Marceau, N., Mongrain, S., Wilson, J.D., 2010. Why do most countries set high tax rates on capital?. Journal of International Economics, 80, 249-259.

[24] Mongrain, S., Wilson, J., 2018. Tax competition with heterogeneous capital mobility. Journal of Public Economics, 167, 177-189.

[25] Narasimhan, C., 1988. Competitive promotional strategies. Journal of Business 61(4), 427-449.

[26] Organization for Economic Cooperation and Development (2004). The OECD's project on harmful tax practices, Paris: OECD

[27] Shilony, Y., 1977. Mixed pricing in oligopoly. Journal of Economic Theory, $14,373-388$.

[28] Thomas, J., Worrall, T., 1994. Foreign direct investment and the risk of expropriation. Review of Economic Studies, 61, 81-108.

[29] Varian, H.R., 1980. A model of sales. American Economic Review, 70, 561569.

[30] Wang, X., 2004. Tax evasion, tax competition and gains from discrimination with equilibrium mixed strategies. Economics Letters 83(3), 377-381.

[31] Wilson, J., 2005. Tax competition with and without preferential treatment of a highly mobile tax base, in The challenges of Tax Reform in a Global Economy, edited by James Alm, Jorge Martinez-Vazquez, and Mark Rides, Springer.

[32] Zodrow, G., 2010. Capital Mobility and Capital Tax Competition, 63, 865901

\section{Appendix}

Proof of Lemma 1. Note that each country can set a tax rate of 1 and receive a tax revenue of 1 from the domestic capital base. Therefore, the equilibrium tax revenue should be at least 1 . The proof is easy. Suppose country $A$ and country $B$ set the tax rates $t_{a}$ and $t_{b}$, respectively. Consider a symmetric pure strategy Nash equilibrium such that $t_{a}=t_{b}$. Suppose $t_{a}=t_{b}>\frac{1}{3}$. Country $A$ 
can deviate and set a tax rate $t_{b}-\epsilon$ for arbitrarily small $\epsilon>0$ and do better. Suppose $t_{a}=t_{b}=\frac{1}{3}$. Country $B$ can deviate and set a tax rate marginally below and do better. Now consider an asymmetric pure strategy Nash equilibrium where $p_{a}>P_{b}$. Country $B$ can increase its tax to $p_{b}+\frac{p_{a}-p_{b}}{2}$ and does better. Hence, no symmetric or asymmetric pure strategy Nash equilibrium exists.

Proof of Lemma 4. We follow Propositions 2-5 in Narasimhan (1988) to prove the uniqueness. Let $S_{a}$ and $S_{b}$ be equilibrium strategy sets of country $A$ and country $B$, respectively.

Step 1. The strategy sets $S_{a}$ and $S_{b}$ are convex. Proof. First, we show that there are no holes in $T=S_{a} \cap S_{b}$. Let $\hat{T}=\inf (T)$ and $\hat{\hat{T}}=\sup (T)$. We show that there is no interval $I=\left(T^{k}, T^{h}\right)$, such that, for $\hat{T}<T^{k}<T^{h}<\hat{\hat{T}}$ and for $T \in I, T \notin T$. This could happen when one of the countries randomizes over the interval $I$ and the other does not or when neither country randomizes over the interval $I$. We show that neither of these two is possible.

First, we show that if country $B$ sets $t_{b} \in T$ with zero probability then so does country $A$. Let us define $t^{1}$ and $t^{2}$ as

$$
\begin{aligned}
& t^{1} \in S_{b}, \text { and } t^{1}=\sup \left(t \mid t<T^{k}\right) \\
& t^{2} \in S_{b}, \text { and } t^{2}=\inf \left(t \mid t>T^{h}\right)
\end{aligned}
$$

It is cleat that the tax revenue of country $A$ when it charges $t^{1}$ and $t^{2}$ respectively, are not equal. Contradicting that we have a mixed strategy Nash equilibrium. Similarly, when both countries do not randomize over the set $T$, the tax revenues at $t^{1}$ and $t^{2}$ are not equal. This proves that $S_{a} \cap S_{b}$ is convex.

Now we show that $T^{\prime}=S_{a}-S_{a} \cap S_{b}$ is convex. As before define $\hat{T}=$ $\inf \left(T^{\prime}\right)$ and $\hat{\hat{T}}=\sup \left(T^{\prime}\right)$. Suppose $\inf \left(T^{\prime}\right)<\inf \left(S_{b}\right)$. This cannot happen because country $A$ can increase its tax revenue by shifting probability to inf $\left(S_{b}\right)$. Therefore, a set where country $A$ randomizes but country $B$ does not should be at the upper end or the lower end. But this cannot happen because country $A$ does not receive an equal tax revenue at the upper end and the lower end of the hole. Similarly, we can show that $T^{\prime}=S_{b}-S_{a} \cap S_{b}$ is convex.

Step 2. Neither country can have a mass point at the interior of other's support.

Proof. Suppose country $B$ has a probability mass of $m$ at $p_{b}$ that lies in the interior of country $A$ 's support. Given $p_{b}$ lies in the interior of country $A$ 's support, there exist an arbitrarily small $\epsilon>0$. such that the set $\left(p_{b}-\epsilon, p_{b}+\epsilon\right)$ lies in the interior of country $A$ 's support. Country $A$ can do better by moving probability from $p_{b}+\epsilon$ to $p_{b}-\epsilon$ because by reducing its tax rate by an arbitrarily small margin, it undercuts the tax rate of country $B$ by a discrete positive probability. Therefore, we conclude that a country cannot have a mass point at the interior of the other's support.

Step 3. Neither country can have a mass point at the lower end of the other's support.

Proof. The argument is similar to that in Step 2. Note that in equilibrium the tax revenue of country $A$ is strictly positive. Therefore, the infimum of the 
support of country $A$ is strictly positive. Suppose country $B$ has a mass point at the lower end of country $A$ 's support. Country $A$ can reduce its tax rate by an arbitrarily small margin $\epsilon>0$, and increase its probability of attracting the investor with discrete positive probability. This increases country $A$ 's tax revenue. This contradicts that we have a mixed strategy Nash equilibrium.

Step 4. Neither country can have a mass point at the upper boundary of the other's support when the other country has a mass point at the boundary. Proof. The argument is simple. When a country has a mass point at the upper boundary of the support, the competitor is better off setting the tax rate at the boundary point with probability zero and lowering its tax rate arbitrarily below the boundary point.

Step 5. Strategy sets $S_{a}$ and $S_{b}$ are identical. When one country has a mass point at $\sup \left(S_{i}\right), i \in(A, B)$, then country $j$ sets $t_{j}=\sup \left(S_{i}\right)$ with probability zero. Proof. Assume to the contrary that $S_{a}$ and $S_{b}$ are not identical. Without loss of generality suppose $S_{b} \subset S_{a}$. From the earlier discussion we know that a set where country $A$ randomizes but country $B$ does not should be either at the upper end or the lower end of country $B$ 's support. Suppose the set lies to the upper end of country $B$ 's support. Define $T=S_{a}-S_{a} \cap S_{b}$. Because strategy sets are convex, the set $T \equiv\left(\sup \left(S_{a}\right), T\right)$ is convex. But country $A$ does better by shifting probability from the set $T$ to $\sup \left(S_{a}\right)$. Contradicting that we have a mixed strategy Nash equilibrium. Similarly, we can show that such an interval cannot exist to the lower end of country B's support. Therefore, we conclude that two strategy sets are identical. It is easy to argue that when one country has a mass point at the supremum of the support then the other country does better by setting the tax rate with probability zero at the supremum and setting a tax rate arbitrarily below.

Step 6. $\sup \left(S_{a}\right)=\sup \left(S_{b}\right)=1$.

Proof. The argument is simple. Suppose $\sup \left(S_{a}\right)=\sup \left(S_{b}\right)=r<1$. When a country sets the tax rate at the supremum of the support, the other country undercuts its tax rate with probability one. Therefore, the tax revenue is equal to $r<1$. The tax revenue is equal to 1 when a country sets the tax rate equal to 1. Contradicting that we have a mixed strategy Nash equilibrium.

Step 7. Only country $A$ can have a mass point at the supremum of its support.

Proof. We have assumed that country $A$ has one unit of domestic capital base, and country $B$ has no domestic capital base. From the previous discussion, the supremum of the support is equal to 1 . When country $A$ has a probability mass at the supremum of the support it receives tax revenues of amount 1 from the domestic capital base. Now assume to the contrary that country $B$ has a probability mass at the supremum of the support. From the earlier discussion, country $A$ cannot have a mass point at the supremum. Therefore, country $A$ undercuts the tax rate of country $B$ with probability 1 . The tax revenue of country $B$ is zero because it has no domestic capital base. This is a contradiction because equilibrium tax revenues of both countries are strictly positive.

This proves that the mixed strategy Nash equilibrium described in Lemma 4 is unique. 
Proof of Proposition 1. We prove Lemma 6 in Steps 1-4.

Step 1. The strategy sets $S_{a}$ and $S_{b}$ are convex.

Proof. First, we show that $S_{a} \cap S_{b}$ is convex. Let $F_{a}$ and $F_{b}$ be distributions of taxes over the support of country $A$ and country $B$ that are possibly non-convex. Let $\hat{T}_{a}=\inf \left(S_{a}\right)$, and $\hat{\hat{T}}_{a}=\sup \left(S_{a}\right)$. Suppose there exist $\hat{T}_{a}<t_{1}<t_{2}<\hat{\hat{T}}_{a}$ such that country $B$ does not set taxes with probability in the range $\left(t_{1}, t_{2}\right)$. First, we will show that when country $B$ does not randomize over a set then country $A$ also does not randomize over the set. Let us define $t_{1}^{s}$ as

$$
t_{1}^{s}=\sup \left\{t, \text { such that } t \leq t_{1}, t \in S_{a} \cap S_{b}\right\}
$$

Similarly define $t_{2}^{i}$ as

$$
t_{2}^{i}=\inf \left\{t, \text { such that } t \geq t_{2}, t \in S_{a} \cap S_{b}\right\}
$$

Define $x \equiv F_{b}\left(t-\frac{1}{2}\right)$, and $y \equiv 1-F_{b}\left(t+\frac{1}{2}\right)$. When country $A$ sets a tax rate $t$, it does not attract an investor with probability $x$, it attracts both investors with probability $y$, and it attracts one investor with probability $1-x-y$. Note that $0 \leq x, y, z \leq 1$. The tax revenue of country $A, T R_{a}$, when it sets $t_{a}=t_{1}^{s}$, is equal to

$$
T R_{a}\left(t_{1}^{s}\right) \equiv x+\left(1+t_{1}^{s}\right)(1-x-y)+2\left(1+t_{1}^{s}\right) y .
$$

Now consider the tax revenue of country $A$ when it sets $t_{a}=t_{2}^{i}$. Let $t_{2}^{i}=t_{1}^{s}+\Delta$. When country $A$ increases its tax rate, the probability of not attracting an investor increases. Let $x^{\prime}=x+\Delta^{1}$, where $\Delta^{1} \geq 0$. When country $A$ increases the tax rate, the probability of attracting both investors decreases. Define $y^{\prime}=y-\Delta^{2}$, where $\Delta^{2} \geq 0$. The tax revenue of country $A$ when it sets $t_{2}^{i}=t_{1}^{s}+\Delta$ is $T R_{a}\left(t_{2}^{i}\right) \equiv x^{\prime}+\left(1+t_{2}^{i}\right)\left(1-x^{\prime}-y^{\prime}\right)+2\left(1+t_{2}^{i}\right) y^{\prime}$. Substituting for $t_{2}^{i}, x^{\prime}$, and $y^{\prime}$ we obtain

$$
T R_{a}\left(t_{2}^{i}\right) \equiv x+\Delta^{1}+\left(1+t_{1}^{s}+\Delta\right)\left(1-x-y-\Delta^{1}+\Delta^{2}\right)+2\left(1+t_{1}^{s}+\Delta\right)\left(y-\Delta^{2}\right) .
$$

It is easy to verify from (12) and (13) that $T R_{a}\left(t_{2}^{i}\right) \neq T R_{a}\left(t_{1}^{s}\right)$. The revenue gain from increase in the probability of attracting no investor in period 1 , is completely offset by the decrease in probability of attracting one investor. The increase in gain from increase in the probability of attracting one investor is less than the loss of revenue from fall in probability of attracting both investors. Contradicting that we have a mixed strategy Nash equilibrium. It also follows that when neither country $A$ nor country $B$ randomizes over the set considered above then $T R_{a}\left(t_{2}^{i}\right) \neq T R_{a}\left(t_{1}^{s}\right)$. Contradicting that we have a mixed strategy Nash equilibrium.

Similarly, we can show that $S_{a}-S_{a} \cap S_{a}$ and $S_{b}-S_{a} \cap S_{b}$ are convex.

Step 2. No country sets a negative tax rate in the equilibrium, that is, $\inf \left(S_{i}\right) \geq 0, i \in(A, B)$.

Proof. From (8), it is clear that a country is not willing to offer a tax rebate in period 1 to attract one investor. The difference in tax revenues in period 2 
when it attract two investors compared to the case when it doesn't attract any investor is equal to 1 . Therefore, the minimum tax rate a country is willing to set in period 1 to attract both investors is equal to $-\left(\frac{1}{2}\right)$. Therefore, any tax rate lower than $-\left(\frac{1}{2}\right)$ are strictly dominated. Suppose country $B$ sets a tax rate less than 0 , that is, $-\frac{1}{2} \leq \hat{T}_{b}=\inf \left(S_{b}\right)<0$. For any tax rate $t_{a}$ such that $t_{a}<\frac{1}{2}$, the best response of country $B$ is to set $t_{b}=t_{a}+\frac{1}{2}$. For any tax rate $t_{a}$ such that $t_{a}>\frac{1}{2}$, the best response of country $B$ is to set $t_{b}=t_{a}-\frac{1}{2}>0$. Therefore, a negative tax rate is not a best response to any tax rate of country $B$. Therefore, iterated elimination of strictly dominated strategies eliminate negative tax rates.

A country cannot set a tax rate greater than 1 . Therefore, the maximum length of the support is equal to 1 . This also means that no where on the support, a country is undercutting the tax rate of the competitor by a margin of $\frac{1}{2}$, and at the same time, it is being undercut by a margin of $\frac{1}{2}$ by the competitor.

Step 3. The length of the support of both countries is equal to 1 , that is, $\inf \left(S_{i}\right)=0$ and $\sup \left(S_{i}\right)=1$, for $i \in(A, B)$.

Proof. Suppose to the contrary that $S_{i} \subset[0,1]$. Then there exist an interval $I_{1} \equiv \frac{1}{2}-\epsilon$ or $I_{2} \equiv \frac{1}{2}+\epsilon$ such that a country is not undercutting the tax rate of the competitor by a fraction of $\frac{1}{2}$, and at the same time, its tax rate is not being undercut by a margin of $\frac{1}{2}$. If that set is $I_{1}$ then the country can shift probability from $I_{1}$ to $\sup \left(I_{1}\right)$ and do better. Contradicting that we have a mixed strategy Nash equilibrium. Therefore, we conclude that inf $\left(S_{i}\right)=0$ and $\sup \left(S_{i}\right)=1$ for $i \in(A, B)$.

Step 4. There is no probability mass anywhere on the support of country $i \in(A, B)$.

Proof. We know that both countries randomize over the set $[0,1]$. There can be three possible cases:

(i) country $B$ sets $t_{b} \in\left(\frac{1}{2}, 1\right)$ with a probability mass, $m_{b}$. However, there is no probability mass over the set $\left(t_{b}-\frac{1}{2}-\epsilon, t_{b}-\frac{1}{2}+\epsilon\right)$, for arbitrarily small $\epsilon>0$. In this case the tax revenue of country $A$ at $t_{b}=t_{b}-\frac{1}{2}-\epsilon$ and $t_{b}=t_{b}-\frac{1}{2}+\epsilon$ are not equal. Contradicting that we have a mixed strategy Nash equilibrium.

(ii) country $B$ sets $t_{b} \in\left(0, \frac{1}{2}\right)$ with a probability mass, $m_{b}$. However, there is no probability mass over the set $\left(t_{b}+\frac{1}{2}-\epsilon, t_{b}+\frac{1}{2}+\epsilon\right)$, for arbitrarily small $\epsilon>0$. In this case the tax revenue of country $A$ at $t_{b}=t_{b}+\frac{1}{2}-\epsilon$ and $t_{b}=t_{b}+\frac{1}{2}+\epsilon$ are not equal. Contradicting that we have a mixed strategy Nash equilibrium.

(iii) country $B$ sets $t_{b} \in\left(0, \frac{1}{2}\right)$ with a probability mass of $m_{b}^{1}$, and also sets $t_{b}+\frac{1}{2}$ with a probability mass of $m_{b}^{2}$. In this at least one of the two conditions is true; (i) the tax revenue of country $A$ at $t_{b}-\epsilon$ and $t_{b}+\epsilon$ are not equal for arbitrarily small $\epsilon>0$, or (ii) the tax revenue of country $A$ at $t_{b}+\frac{1}{2}-\epsilon$ and $t_{b}+\frac{1}{2}+\epsilon$ are not equal for arbitrarily small $\epsilon>0$. Contradicting that we have a mixed strategy Nash equilibrium.

This proves that the mixed strategy Nash equilibrium is unique. 